\title{
Hierarchical microstructure of nanoparticles of calcium carbonate/epoxy composites: Thermomechanical and surface properties
}

\author{
T. B. Miranda ${ }^{1}$, G. G. Silva ${ }^{2}$ \\ ${ }^{1}$ Departamento de Engenharia Química, Universidade Federal de Minas Gerais, Brazil \\ ${ }^{2}$ Departamento de Química and CTNano, Universidade Federal de Minas Gerais, Brazil
}

Received 2 June 2019; accepted in revised form 9 August 2019

\begin{abstract}
Calcium carbonate nanoparticles of calcite structure and nanometric size were successfully synthesized by mechanochemical processing using low energy mill $(100 \mathrm{rpm})$. Transmission electron micrographs demonstrated that the nanoparticles tend to form agglomerates of approximately $1 \mu \mathrm{m}$ due to their high surface energy. A study of structure and properties of composite materials resulting from the addition of $\mathrm{CaCO}_{3}$ nanoparticles at concentrations of $1,2.5$ and $5 \mathrm{wt} \%$ to epoxy resin was made. Epoxy $/ 1 \mathrm{wt} \% \mathrm{CaCO}_{3}$ and epoxy $/ 2.5 \mathrm{wt} \% \mathrm{CaCO}_{3}$ composites displayed an increase of 8 and $12{ }^{\circ} \mathrm{C}$ in glass transition temperature $\left(T_{\mathrm{g}}\right)$, respectively. Scanning electron microscopy images of composites revealed a hierarchical structure of micrometric sized extended aggregates of nanometric calcium carbonate particles homogeneously distributed in the polymer matrix. This morphology explains the increase in hydrophobicity, as well as gains in Young's moduli, which were greater than 59\% with respect to the neat epoxy as measured by Nanoindentation. Therefore, this work demonstrates that the optimum range of concentration up to $2.5 \mathrm{wt} \%$ of high-quality nano $\mathrm{CaCO}_{3}$ guarantees thermal, mechanical and surface significant improvements associated with a hierarchical microstructure-nanostructure, which ultimately extend the possibilities of application of epoxy materials for nowadays challenges.
\end{abstract}

Keywords: nanocomposites, $\mathrm{CaCO}_{3}$ nanoparticles, epoxy, hierarchical structure, mechanochemical processing

\section{Introduction}

Continuous demand for highly efficient materials encourages innovations on nanotechnology and nanocomposites manufacturing. The addition of calcium carbonate to epoxy resin reduces production costs and may improve the polymer's performance. The challenge, however, is to ensure the transfer of nanoparticle's properties to the matrix without the tradeoff of in the characteristics of the polymer.

Epoxy is a thermoset polymer with good adherence and dimensional stability, interesting mechanical, chemical and corrosion resistance and fine processability $[1,2]$. According to its formulation, epoxy is used as adhesives, coatings and engineering composites [3]. Moreover, nano-calcium carbonate has low cost with respect to other nanoparticles, low aspect ratio and high surface area [4]. They are commonly used as filler, extender or pigment for paper, paint, rubber, and plastics in various industries $[5,6]$. Their introduction into polymer matrix by a small amount (less than $5 \mathrm{wt} \%$ ) can enhance the composite's properties depending on the nanoparticle's shape, particle and aggregate size, surface characteristics and degree of dispersion $[4,7]$.

Nanoparticles of calcium carbonate can be synthesized by mechanochemical processing according to Equation (1) [5]. 


$$
\begin{gathered}
\mathrm{CaCl}_{2(\mathrm{~s})}+\mathrm{Na}_{2} \mathrm{CO}_{3(\mathrm{~s})}+10.3 \mathrm{NaCl}_{(\mathrm{s})} \\
\mathrm{CaCO}_{3(\mathrm{~s})}+12.3 \mathrm{NaCl}_{(\mathrm{s})}
\end{gathered}
$$

Mechanical activation of solid-state displacement reactions occurs by milling powdered reactants, which undergo microstructural refinement. The energy deriving from ball/powder collisions promotes continuous deformation, fracture, and bonding of reactants' particles $[5,8]$. The plastic deformation of the particles initially occurs by the development of shear bands, which decompose into sub-grains separated by low-angle grain boundaries. With further milling, the sub-grain size decreases and nanometer-sized subgrains become randomly oriented and separated by high angle boundaries [9-11]. At this point, chemical reactions take place at the interface of the grain boundaries, producing product particles at the same nanoscale of the reactants [11, 12]. Mechanochemical processing can synthesize a wide range of nanoparticles including metals, oxides, sulfides, and carbonates $[5,11-13]$.

To avoid agglomerations $\mathrm{NaCl}$ is added in excess and works as a salt matrix preventing the particles percolation and coalescence by the milling process, as well as by the posterior heat treatment. In addition, the volume fraction of the particles of the desired product is kept less than $10 \%$ as to ensure that there is a larger salt matrix volume to disperse the nanoparticles $[5,12]$. Furthermore, mechanochemical processing is a simple and highly effective method in reducing the degree of agglomeration during the particle growth stage and can be scaled for a larger production [5,12-14].

Many articles and scientific papers evaluated the mechanical properties of epoxy/nano $\mathrm{CaCO}_{3}$ composites. Jain et al. [15] (2009) produced an epoxy $/ 4 \mathrm{wt} \%$ nano $\mathrm{CaCO}_{3}$ of greater stiffness, hardness and glass transition temperature compared to the neat epoxy. Li et al. [16] (2005) concluded that $\mathrm{CaCO}_{3}$ nanoparticles added at concentrations lower than $6 \mathrm{wt} \%$ to epoxy resin increases the impact resistance. Shimpi and Mishra [17] (2012) also reported an improvement in mechanical, as well as thermal properties of epoxy by increasing the filler content.

Therefore, in this study, calcium carbonate nanoparticles were synthesized by mechanochemical processing and epoxy/nano $\mathrm{CaCO}_{3}$ composites were produced aiming to obtain materials with enhanced thermomechanical and surface properties.

\section{Experimental procedure}

\subsection{Materials}

The starting chemical high purity calcium chloride $\left(\mathrm{CaCl}_{2}\right)$, sodium carbonate $\left(\mathrm{Na}_{2} \mathrm{CO}_{3}\right)$ and sodium chloride $(\mathrm{NaCl})$ were purchased from Synth (São Paulo, Brazil). The epoxy pre-polymer diglycidyl ether of bisphenol A (DGEBA, trade name: MC 130, with a molecular weight of $368-380 \mathrm{~g} / \mathrm{mol}$ ) and the curing agent triethylenetetramine (TETA, trade name: FD 129) were supplied by EpoxyFiber (Rio de Janeiro, Brazil).

\subsection{Synthesis of $\mathrm{CaCO}_{3}$ nanoparticles}

The starting chemicals $\mathrm{CaCl}_{2}, \mathrm{Na}_{2} \mathrm{CO}_{3}$, and $\mathrm{NaCl}$ were dried at $180^{\circ} \mathrm{C}$ for 8 hours to remove moisture before their usage. The reactants were sealed in a hardened steel vial with steel balls of 7, 12 and $21 \mathrm{~mm}$. Milling was performed with a low energy mill U.S. STONEWARE (100 rpm) using a ball to powder mass ratio of 10:1 under air atmosphere for 24 hours. The as-milled powders were subject to heat-treatment at $350^{\circ} \mathrm{C}$ for 1 hour to improve crystallinity. Then, the $\mathrm{NaCl}$ phase was removed by washing the powder with de-ionized water, using an ultrasonic bath and a vacuum filter. Finally, the washed powder was dried at $60^{\circ} \mathrm{C}$ for 12 hours to obtain the final powdered product.

\subsection{Characterization of $\mathrm{CaCO}_{3}$ nanoparticles}

The phase composition was evaluated by X-ray diffraction measurements (XRD-7000 Shimadzu) using $\mathrm{Cu}-\mathrm{K} \alpha$ radiation $(\lambda=1.54184 \AA)$. The chemical structure was analyzed using Fourier transform infrared spectrometer (Spotlight 400N FTIR Imaging System) in the ATR mode with $\pm 4 \mathrm{~cm}^{-1}$ resolution. The thermal stability of the $\mathrm{CaCO}_{3}$ particles was characterized using Q5000 - IR TA Instruments in a nitrogen atmosphere at a heating rate of $10^{\circ} \mathrm{C} / \mathrm{min}$. After dispersing the powder in ethanol and depositing it on a carbon plate, the particle's morphology was investigated by a transmission electron microscopy (TEM) using Tecnai G2 - 20 FEI at $200 \mathrm{kV}$. The hydrodynamic diameter and the polydispersity index were determined by dynamic light scattering (DLS) analysis using Litesizer 500 Anton Paar. The nanoparticle powder was previously dispersed in ethanol, forming a suspension of $100 \mathrm{ppm}$. The measurements were performed using a laser wavelength of $660 \mathrm{~nm}$ at $25^{\circ} \mathrm{C}$. At this wavelength, the refractive 
index and the UV absorbance value of calcium carbonate are 1.6543 and 0 , respectively [18-20].

\subsection{Preparation of epoxy/nano $\mathrm{CaCO}_{3}$ composites}

Neat epoxy and nanocomposites were prepared by adding $1,2.5$ and $5 \mathrm{wt} \%$ of $\mathrm{CaCO}_{3}$ nanoparticles to epoxy pre-polymer diglycidyl ether of bisphenol A (DGEBA). The particles were dispersed using a threeroll mill Exakt 80E (Exakt Technologies, INC., Oklahoma City, United States) at a rotation of $150 \mathrm{rpm}$. The mixture of pre-polymer and $\mathrm{CaCO}_{3}$ nanoparticles cross the roll-mill 8 times through a gap of $5 \mu \mathrm{m}$ between the rolls. This methodology of dispersing nanoparticles with the three-roll mill was optimized by CTNano group (BH-TEC, Universidade Federal de Minas Gerais) [21]. Then, the homogeneous mixture was degassed for 2 hours. Finally, the curing agent triethylenetetramine (TETA) at a ratio of phr 14 (parts by mass of curing agent for one hundred parts of resin) was added and the mixture was poured into a silicone mold and was left to cure at room temperature for 24 hours. Isothermal post-cure treatment was performed at $100^{\circ} \mathrm{C}$ for 2 hours in an air oven [22]. The specimens were polished to give the final finishing.

\subsection{Characterization of epoxy/nano $\mathrm{CaCO}_{3}$ composites}

Thermal stability was evaluated using Q5000 - IR TA Instruments in a nitrogen atmosphere at a heating rate of $10^{\circ} \mathrm{C} / \mathrm{min}$. In order to determine the dynamic thermomechanical properties, a DMA 242 E Artemis Netzsch was employed in view of performing a threepoint bending flexural test at a frequency of $1 \mathrm{~Hz}$ and a heating rate of $3{ }^{\circ} \mathrm{C} / \mathrm{min}$. DSC analysis was performed using Q2000 TA Instruments to compare the results of glass transition temperature $\left(T_{\mathrm{g}}\right)$ with those obtained by DMA analysis. Thermogravimetric, DMA and DSC analyses were accomplished in replicates. Morphological characterization was carried out on the fracture region of specimens, coated with pure carbon, by FEG-Quanta 200 FEI scanning electron microscopy (SEM) operated at $30 \mathrm{kV}$. The TEM micrographs of epoxy $/ 2.5 \mathrm{wt} \%$ composite were taken after an ultramicrotomy process using Tecnai G2 $20 \mathrm{FEI}$ at $200 \mathrm{kV}$. Young's modulus and hardness of composites were calculated using the Olive-Pharr method [23] from nanoindentation tests (performed in 20 points of the samples) using MFP-3D-AS
Asylum Research AFM with a Berkovich diamond tip and a scanning area of $50 \mu \mathrm{m} \times 50 \mu \mathrm{m}$. The method kept the maximum load of $1 \mathrm{mN}$ for $10 \mathrm{sec}-$ onds before unloading. Wettability of composites was accomplished on a Krüss Tantey goniometer and the results correspond to an average of 10 measurements. The surfaces' roughness was also statistically calculated using MFP-3D-AS Asylum Research AFM to study surface properties.

\section{Results and discussion}

\subsection{Characterization of $\mathrm{CaCO}_{3}$ nanoparticles}

The X-ray pattern (Figure 1a) shows the characteristic peaks of calcite at the main $2 \theta$ values presented in Table 1. Scherrer equation was used to calculate the crystallite sizes (Table 1 ) and the average size of crystallite is $24 \mathrm{~nm}[6,24]$.

FTIR analysis was performed to confirm the purity of the nanoparticles. FTIR spectra (Figure 1b) reveals characteristic vibrational bands of $\mathrm{O}-\mathrm{C}-\mathrm{O}$ bond at $713 \mathrm{~cm}^{-1}$ (out-of-plane bend), $874 \mathrm{~cm}^{-1}$ (asymmetric stretch) and $1396 \mathrm{~cm}^{-1}$ (in-plane bend). The combination of the vibrational modes associated with these peaks appears at 1795 and $2515 \mathrm{~cm}^{-1}$ as expected for a pure calcite structure $[25,26]$.

The thermal analysis allows evaluating the presence of water, both moisture and structural, and the purity of the nanoparticles. The TG/DTG curves (Figure 1c) exhibit the high thermal stability of $\mathrm{CaCO}_{3}$ anhydrous nanoparticles reaching $650^{\circ} \mathrm{C}$. Calcium carbonate can show a two-step process of mass loss. In the first step, the mass loss occurs near $100^{\circ} \mathrm{C}$ due to the adsorbed water, which is almost negligible on Figure 1c. In the second step, $\mathrm{CaCO}_{3}$ decomposes into calcium oxide and carbon dioxide [27]. Once more, the thermal analysis showed that there is no substance other than calcium carbonate in the nanomaterial.

Through DLS analysis (Figure 1d), the hydrodynamic diameter and the polydispersity index (PDI) of $\mathrm{CaCO}_{3}$ nanoparticles were evaluated as $1.1 \pm 0.2$ and $0.24 \pm 0.02 \mu \mathrm{m}$, respectively. These results indicate that the nanoparticles have a tendency to agglomerate in suspension, forming aggregates with a micrometric size, but they also reveal a narrow aggregate diameter distribution. Sargheini et al. [6] (2011) also synthesized $\mathrm{CaCO}_{3}$ nanoparticles by mechanochemical processing and reported a mean agglomerate diameter of $12.7 \mu \mathrm{m}$ according to LPSA (laser particle size analyzer) analysis. $\mathrm{CaCO}_{3}$ nanoparticles synthesized by 

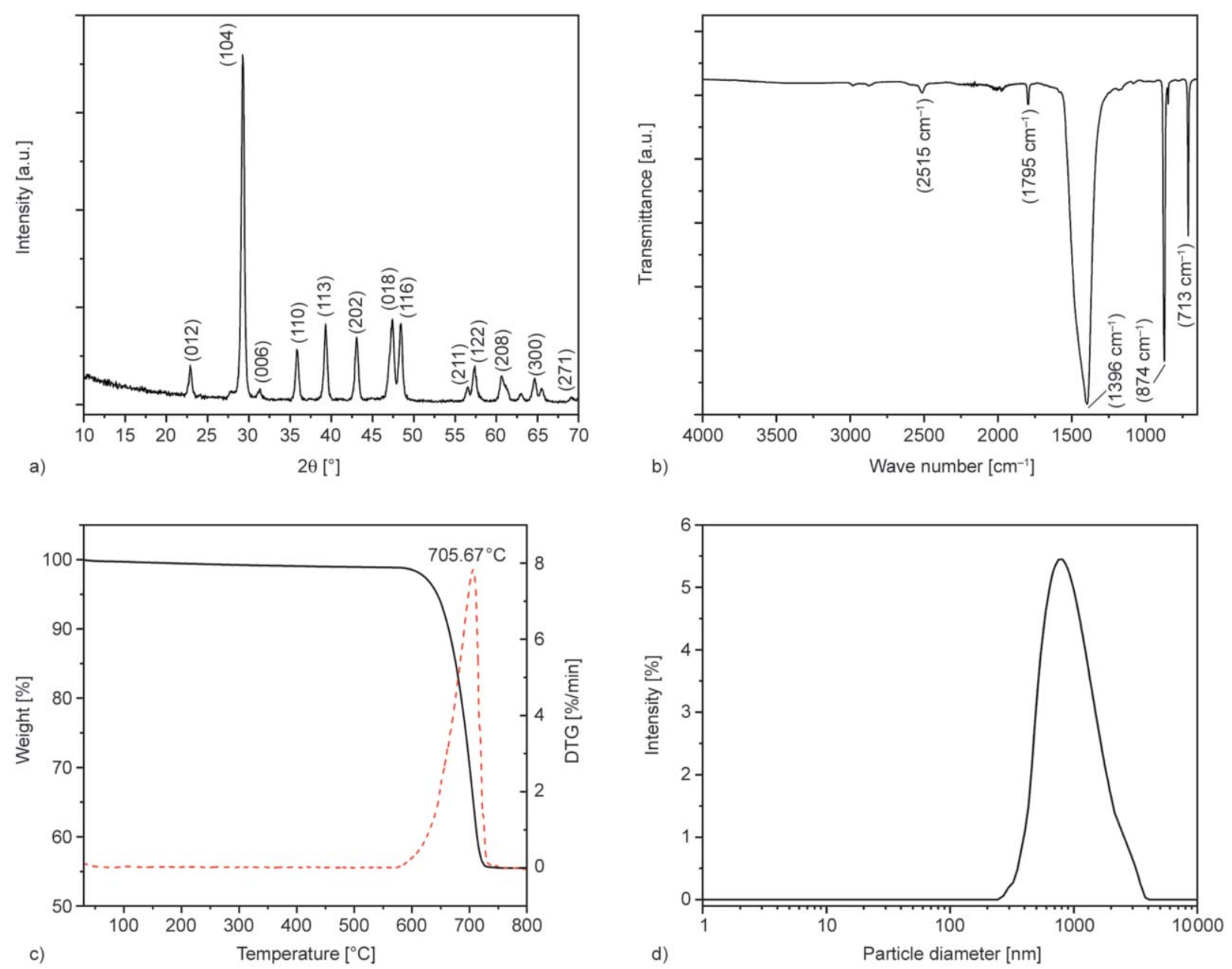

Figure 1. (a) X-ray diffraction pattern of $\mathrm{CaCO}_{3}$ nanoparticles; (b) FT-IR spectra of $\mathrm{CaCO}_{3}$ nanoparticles; (c) TG/DTG curves of $\mathrm{CaCO}_{3}$ nanoparticles; (d) particle diameter distribution from DLS analysis.

Table 1. XRD peak positions of $\mathrm{CaCO}_{3}$ nanoparticles and their respective Miller Indices and crystallite sizes.

\begin{tabular}{|l|l|l|l|l|l|l|l|l|}
\hline $2 \theta$ of peak & 22.90 & 29.25 & 31.35 & 35.80 & 39.30 & 43.05 & 47.40 & 48.45 \\
\hline Miller Index & $(012)$ & $(104)$ & $(006)$ & $(110)$ & $(113)$ & $(202)$ & $(018)$ & $(116)$ \\
\hline Crystallite size $[\mathrm{nm}]$ & 29.3 & 21.2 & 20.9 & 25.3 & 24.3 & 25.3 & 24.9 & 18.5 \\
\hline
\end{tabular}

mechanochemical processing showed a narrower distribution of hydrodynamic diameter than the nanoparticles synthesized through carbonation method by Atta et al. [27] (2016), whose calcium carbonate particles were capped with hydrophobic fatty acids as to control size increments.

The cubic morphology and the nanometric size of $\mathrm{CaCO}_{3}$ particles were evidenced by TEM images (Figure 2). Moreover, the nanoparticles tend to form extended agglomerates (as a bunch of grapes) of approximately $1 \mu \mathrm{m}$ long due to their high surface energy [28-30]. Since the particle's size (62-112 nm) is thrice or more the crystallite size (as calculated from the XRD results), $\mathrm{CaCO}_{3}$ nanoparticles might be composed by several crystallites [24]. Thus, the presence of $\mathrm{NaCl}$ matrix was responsible for preventing particle agglomeration during the growth stage in the synthesis process.

\subsection{Characterization of epoxy/nano $\mathrm{CaCO}_{3}$ composites}

The thermal stability of the epoxy/nano $\mathrm{CaCO}_{3}$ composites was evaluated by TG/DTG thermograms (Figure 3). The thermal stability parameters were summarized in Table 2. These data include the initial decomposition temperature (IDT), determined from the intersection of the two tangents at the first inflection point, the temperature at the maximum degradation rate $\left(T_{\max }\right)$, the mid-point of the degradation $\left(T_{50 \%}\right)$, considered an indicator for structural destabilization 


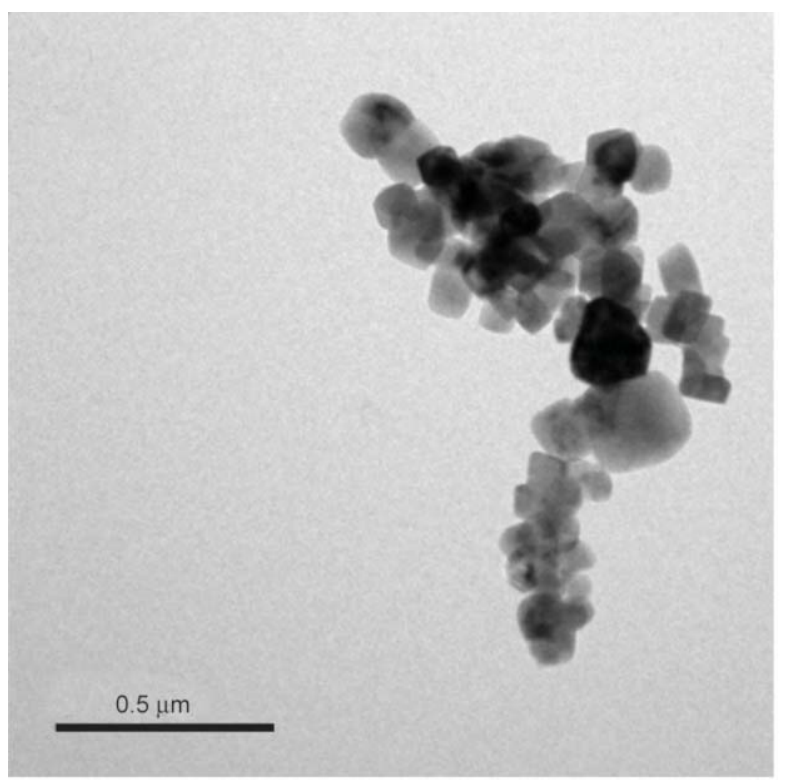

a)

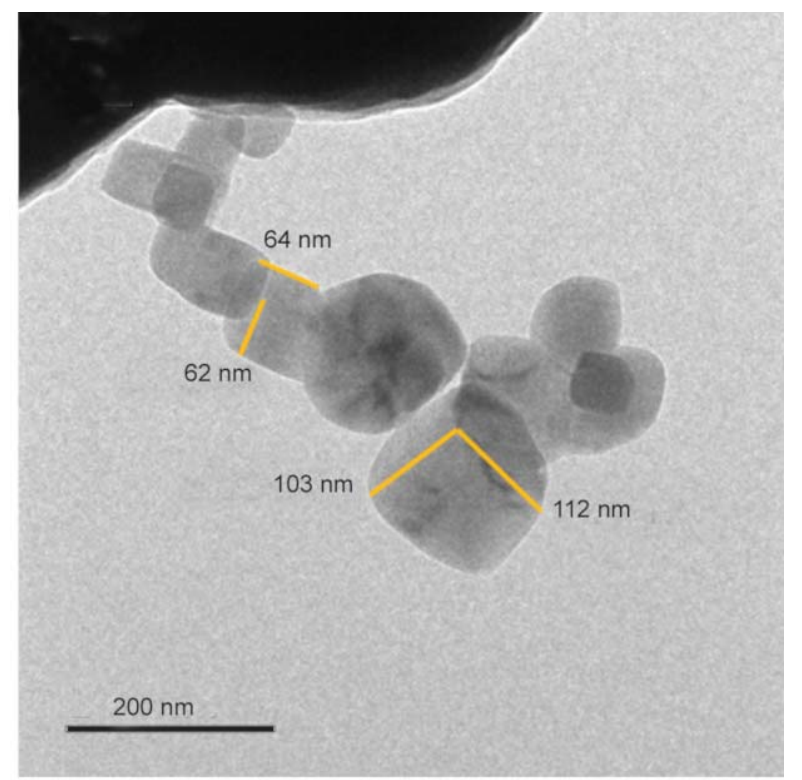

b)

Figure 2. TEM images of $\mathrm{CaCO}_{3}$ nanoparticles with scale bars of: (a) $500 \mathrm{~nm}$ and (b) $200 \mathrm{~nm}$.
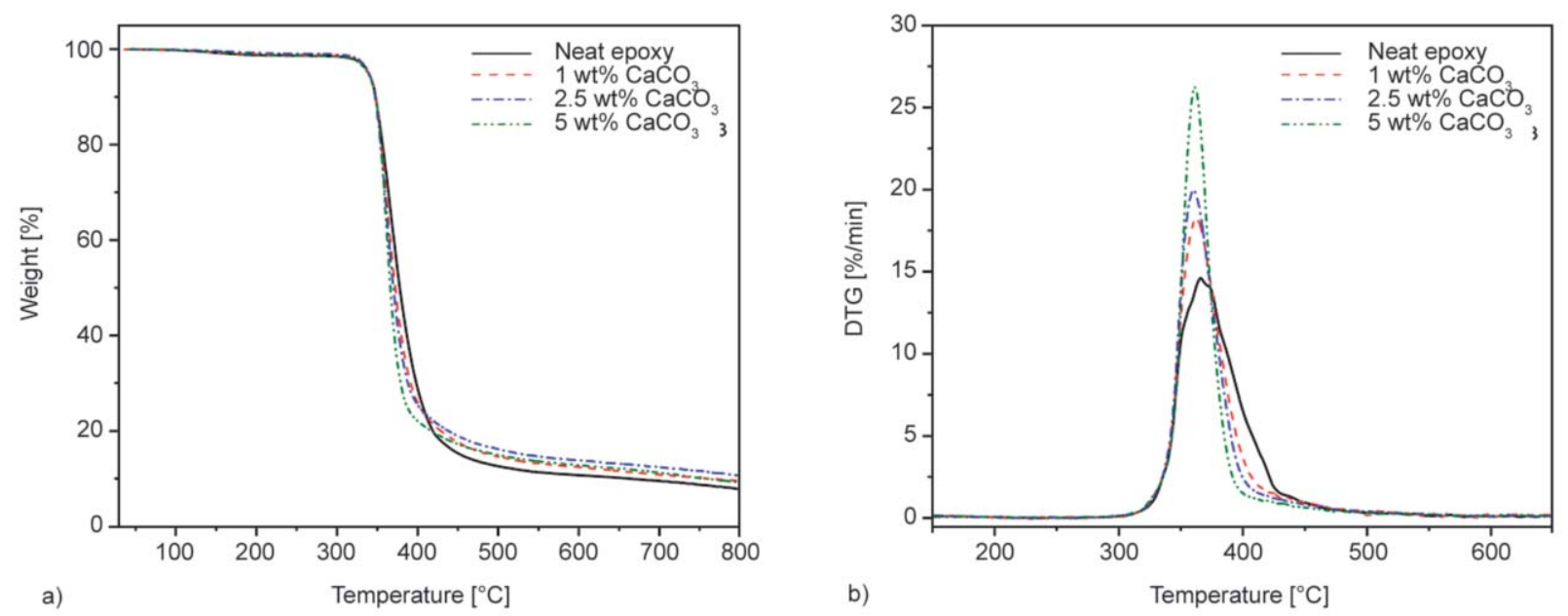

Figure 3. (a) TG curves and (b) DTG curves of neat epoxy and epoxy/nano $\mathrm{CaCO}_{3}$ composites.

Table 2. Parameters from TG/DTG curves of neat epoxy and epoxy/nano $\mathrm{CaCO}_{3}$ composites.

\begin{tabular}{|l|c|c|c|c|}
\hline \multicolumn{1}{|c|}{ Sample } & $\begin{array}{c}\text { IDT } \\
{\left[{ }^{\circ} \mathbf{C}\right]}\end{array}$ & $\begin{array}{c}\boldsymbol{T}_{\max } \\
{\left[{ }^{\circ} \mathbf{C}\right]}\end{array}$ & $\begin{array}{c}\boldsymbol{T}_{\mathbf{5 0}} \\
{\left[{ }^{\circ} \mathbf{C}\right]}\end{array}$ & $\begin{array}{c}\text { Char yield at }_{600}{ }^{\circ} \mathbf{C} \\
{\left[{ }^{\circ} \mathbf{C}\right]}\end{array}$ \\
\hline Neat epoxy & $338.2 \pm 0.1$ & $367.3 \pm 2.6$ & $377.3 \pm 1.0$ & $10.6 \pm 0.2$ \\
\hline $1 \mathrm{wt} \% \mathrm{CaCO}_{3}$ & $339.8 \pm 1.2$ & $362.5 \pm 2.6$ & $371.5 \pm 1.0$ & $12.2 \pm 0.2$ \\
\hline $2.5 \mathrm{wt} \% \mathrm{CaCO}_{3}$ & $342.9 \pm 1.5$ & $360.5 \pm 0.3$ & $370.2 \pm 0.4$ & $14.0 \pm 0.3$ \\
\hline $5 \mathrm{wt} \% \mathrm{CaCO}_{3}$ & $346.6 \pm 0.7$ & $361.2 \pm 1.4$ & $366.1 \pm 0.1$ & $13.0 \pm 0.3$ \\
\hline
\end{tabular}

since $50 \mathrm{wt} \%$ is lost and the char yield, which corresponds to the fraction of non-volatile remaining at $600^{\circ} \mathrm{C}[15,31,32]$.

Neat epoxy and epoxy/nano $\mathrm{CaCO}_{3}$ composites show a single weight loss process in a nitrogen atmosphere. The mass loss is caused by the general breakdown of the chemical bonds of the epoxy chains (including the $\mathrm{C}$-phenyl bonds of the bisphenol A groups) that happens after $350^{\circ} \mathrm{C}[2,33]$.
$\mathrm{CaCO}_{3}$ nanoparticles introduction in epoxy resin did not affect the thermal stability of the polymer, as there was no reduction to the initial decomposition temperature (IDT). The nanoparticles, however, did catalyze the degradation of the composites, which resulted in lower temperatures at the maximum degradation rate $\left(T_{\max }\right)\left(357-365^{\circ} \mathrm{C}\right)$ compared to the neat epoxy $\left(365-370^{\circ} \mathrm{C}\right)$. As a consequence of the catalyst effect of $\mathrm{CaCO}_{3}$ nanoparticles, the mid-point of 
degradation temperature $\left(T_{50 \%}\right)$ decreased, while there was an increase of $\mathrm{CaCO}_{3}$ content. The char yield at $600^{\circ} \mathrm{C}$ also augmented with the rise of $\mathrm{CaCO}_{3} \mathrm{wt} \%$, except for epoxy $/ 5 \mathrm{wt} \% \mathrm{CaCO}_{3}$ composite due to its higher level of aggregation in the matrix, which caused a reduction of the interactions with the polymer chains, leading to a different thermal behavior [31].

The main interactions established among $\mathrm{CaCO}_{3}$ nanoparticles and the epoxy chains are the hydrogen bonds between the $\mathrm{C}=\mathrm{O}$ and the $\mathrm{O}-\mathrm{H}$ of the polymeric chains [34].

DMA results are presented in Figure 4. Figure 4a shows the energy dissipated from the materials, represented by tan delta versus the temperature, indicating the glass transition temperatures $\left(T_{\mathrm{g}}\right)$ as the maximum of the peaks. The $T_{\mathrm{g}}$ increased with $\mathrm{CaCO}_{3}$ nanoparticles content, except for epoxy $/ 5 \mathrm{wt} \% \mathrm{CaCO}_{3}$ composite. The same tendency of $T_{\mathrm{g}}$ determined by DMA is observed using DSC analysis, which is presented in Table 3.

Epoxy $/ 2.5 \mathrm{wt} \% \mathrm{CaCO}_{3}$ composite increased 5 and $12^{\circ} \mathrm{C}$ in $T_{\mathrm{g}}$ from DMA and DSC analysis, respectively, while Shi et al. [34] (2006) reported an increase of $5^{\circ} \mathrm{C}$ for epoxy $/ 15 \mathrm{wt} \% \mathrm{CaCO}_{3}$ composite.

Table 3. Glass transition temperature $\left(T_{\mathrm{g}}\right)$ from DMA and DSC (onset) analysis for neat epoxy and epoxy/ nano $\mathrm{CaCO}_{3}$ composites.

\begin{tabular}{|l|c|c|}
\hline \multicolumn{1}{|c|}{ Sample } & $\begin{array}{c}\boldsymbol{T}_{\mathrm{g}} \text { from DMA } \\
{\left[{ }^{\circ} \mathbf{C}\right]}\end{array}$ & $\begin{array}{c}\boldsymbol{T}_{\mathrm{g}} \text { from DSC } \\
{\left[{ }^{\circ} \mathbf{C}\right]}\end{array}$ \\
\hline Neat epoxy & $136.8 \pm 0.2$ & $116.4 \pm 0.1$ \\
\hline $1 \mathrm{wt} \% \mathrm{CaCO}_{3}$ & $140.5 \pm 0.2$ & $125.2 \pm 0.8$ \\
\hline $2.5 \mathrm{wt} \% \mathrm{CaCO}_{3}$ & $142.0 \pm 0.2$ & $129.0 \pm 0.9$ \\
\hline $5 \mathrm{wt} \% \mathrm{CaCO}_{3}$ & $117.4 \pm 0.2$ & $99.7 \pm 4.4$ \\
\hline
\end{tabular}

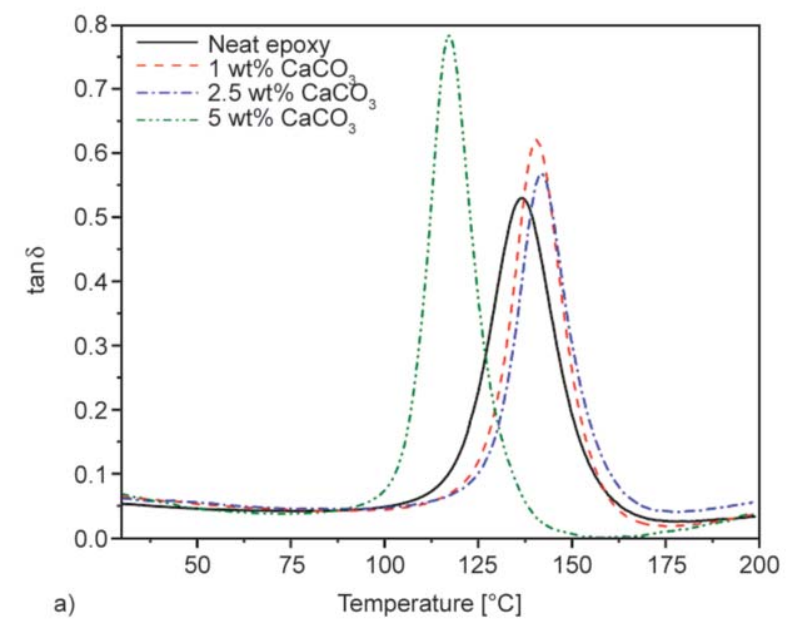

The $T_{\mathrm{g}}$ results show that the incorporation of $\mathrm{CaCO}_{3}$ nanoparticles leads to restricted thermal mobility of the chain segments, which can be associated with interfacial interactions between the filler and the polymer that $[15,31,32]$. In our opinion a combination of factors can be considered to justify the decrease in $T_{\mathrm{g}}$ for the $5 \mathrm{wt} \%$ nanoparticles based composite: i) aggregation withdrawing nanoparticles from the contact with the epoxy chains; ii) aggregates increasing the viscosity of the system and impeding the efficient mixing of the hardener with the resin; and iii) aggregates leading to a surface that acts preventing the complete crosslinking of the epoxy chains [35]. The storage modulus $\left(E^{\prime}\right)$ is exhibited in Figure $4 \mathrm{~b}$. When working at temperatures higher than $120^{\circ} \mathrm{C}$, the composites displayed an elevated storage modulus with respect to the neat epoxy (with the exception of epoxy $/ 5 \mathrm{wt} \% \mathrm{CaCO}_{3}$ composite, which was expected due to its lower $T_{\mathrm{g}}$ and a higher level of particles aggregation).

Figure 5 shows typical SEM micrographs of neat epoxy and epoxy/nano $\mathrm{CaCO}_{3}$ composites. One can observe that the $\mathrm{CaCO}_{3}$ nanoparticles formed agglomerates in the polymer matrix, similar to the structures previously exhibited by TEM images (Figure 2), having an elongated shape resulting from resin processing at three-roll mill. These clusters appear to be homogeneously distributed in the epoxy and can be seen with more details in Figure 6 .

The $\mathrm{CaCO}_{3}$ clusters seem to be well adhered at the matrix indicating a good interaction between both, except for epoxy $/ 5 \mathrm{wt} \% \mathrm{CaCO}_{3}$ composite (Figure $6 \mathrm{~d})$. The increase in nanoparticles content promotes a matrix saturation, as well as an increase of the clusters in size, thus hindering the interactions

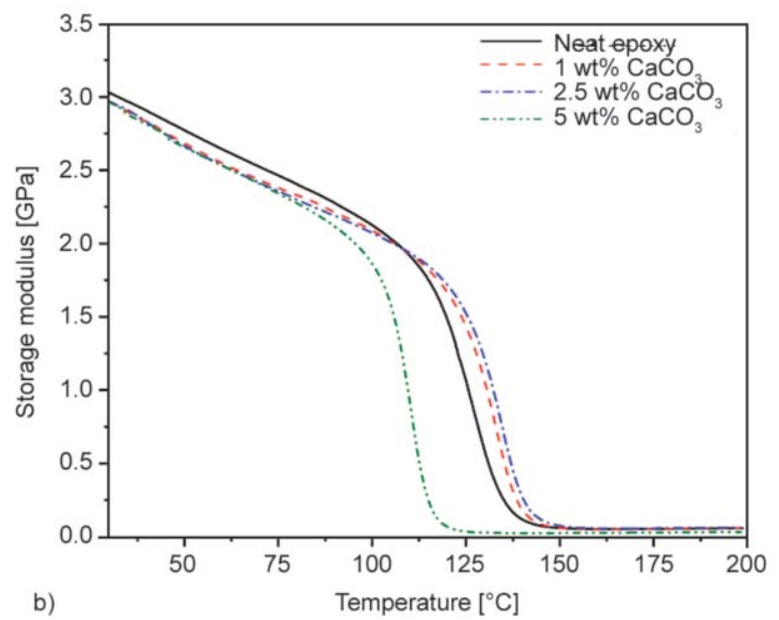

Figure 4. (a) $\tan \delta$ versus temperature and (b) storage modulus of neat epoxy and epoxy/nano $\mathrm{CaCO}_{3}$ composites. 


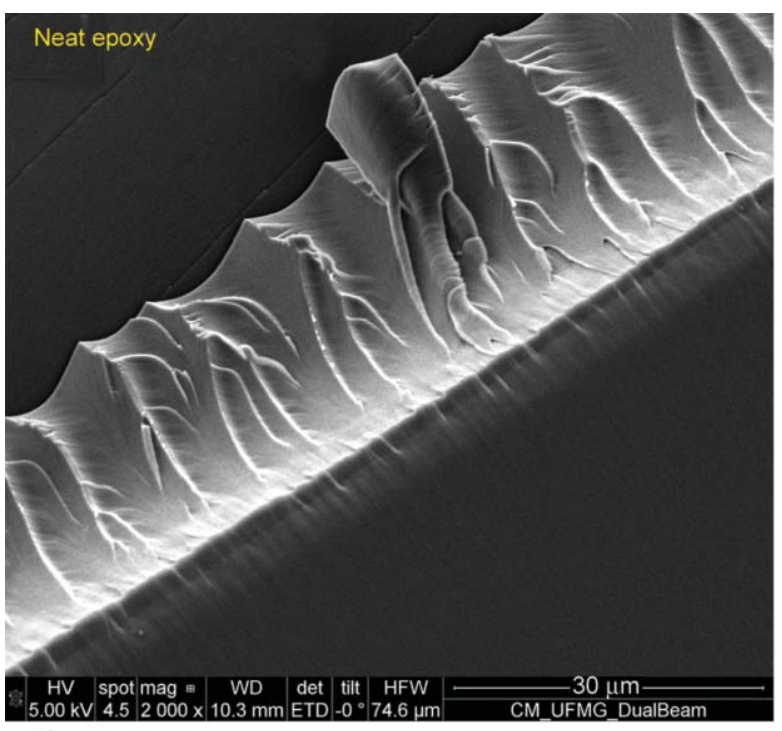

a)

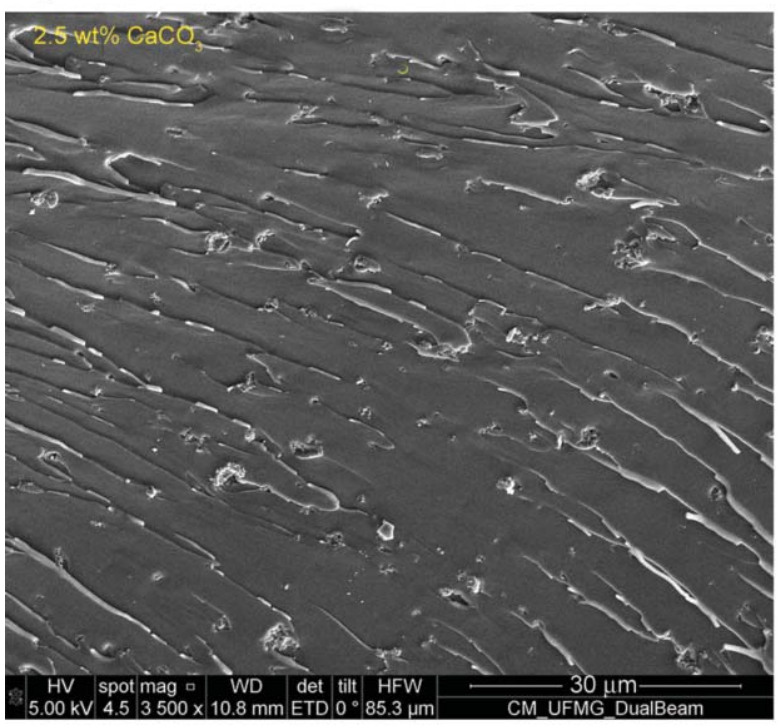

c)

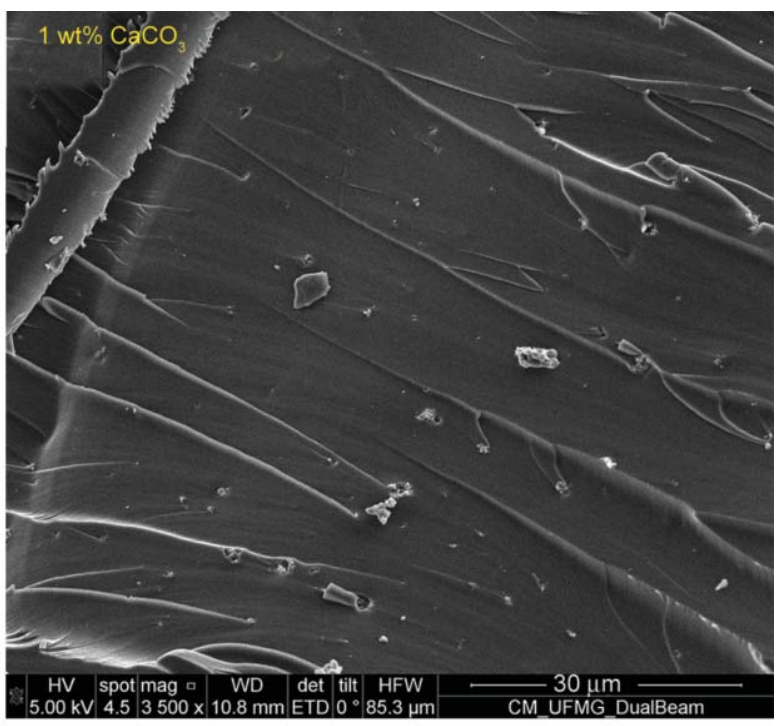

b)

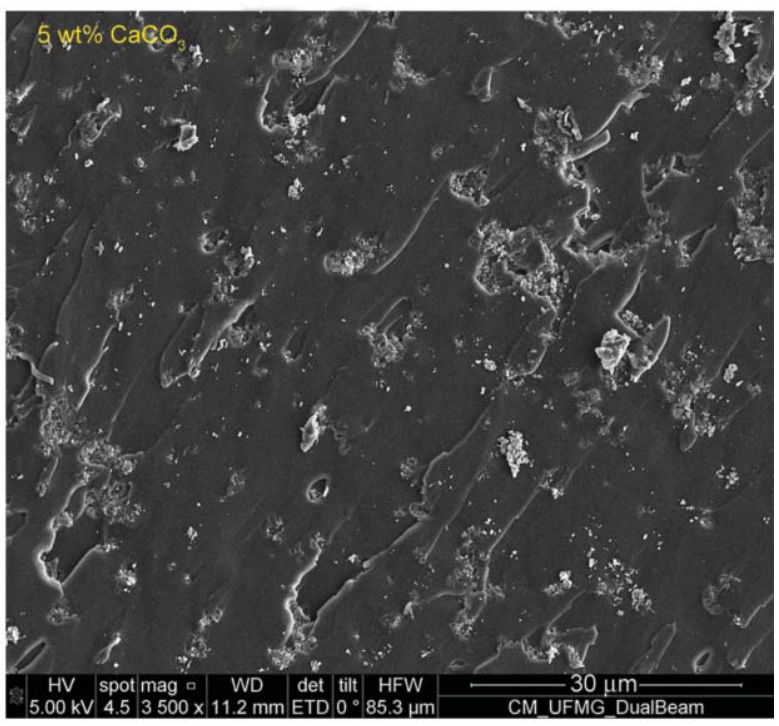

d)

Figure 5. SEM images at $30 \mu \mathrm{m}$ : (a) neat epoxy, (b) epoxy $/ 1 \mathrm{wt} \% \mathrm{CaCO}_{3}$, (c) epoxy $/ 2.5 \mathrm{wt} \% \mathrm{CaCO}_{3}$ and (d) epoxy $/ 5 \mathrm{wt} \%$ $\mathrm{CaCO}_{3}$.

among polymeric chains and nanoparticles. For this reason, the dispersion of the nanoparticles in the matrix becomes more laborious with the increase of the nanomaterial concentration. As a consequence, $5 \mathrm{wt} \%$ $\mathrm{CaCO}_{3}$ addition in the epoxy was characterized by dispersion problems and lead to a decrease in the polymer's performance. Therefore, the critical stage to $\mathrm{CaCO}_{3}$ nanoparticles agglomeration seems to be their dispersion in the epoxy resin due to the compatibility limitation of the nanoparticles with the epoxy carbon chains.

In order to overcome some of the nanoparticles' dispersion problems in the epoxy, solvents are used both to reduce the polymer's viscosity and to aid the percolation of the nanomaterial in the matrix. However, the solvents employed may influence the curing reactions and the structure of the epoxy system. The presence of the residual solvent may modify the curing reaction mechanism affecting the crosslinking density and, consequently, the mechanical behavior of the cured composites. Moreover, the solvent released during the curing can result in porosities and residual stresses, compromising the integrity of the cured material $[36,37]$. Because of these disadvantages and the established interface interactions of the $\mathrm{CaCO}_{3}$ nanoparticles with the polymer chains, it was preferred not to employ solvents in the filler dispersion aiming to preserve the epoxy characteristics and performance.

TEM images of thin slices of epoxy $/ 2.5 \mathrm{wt} \%$ composite (Figure 7) exhibit the nanoparticles' dispersion in the polymer matrix. Regions of well-dispersed 


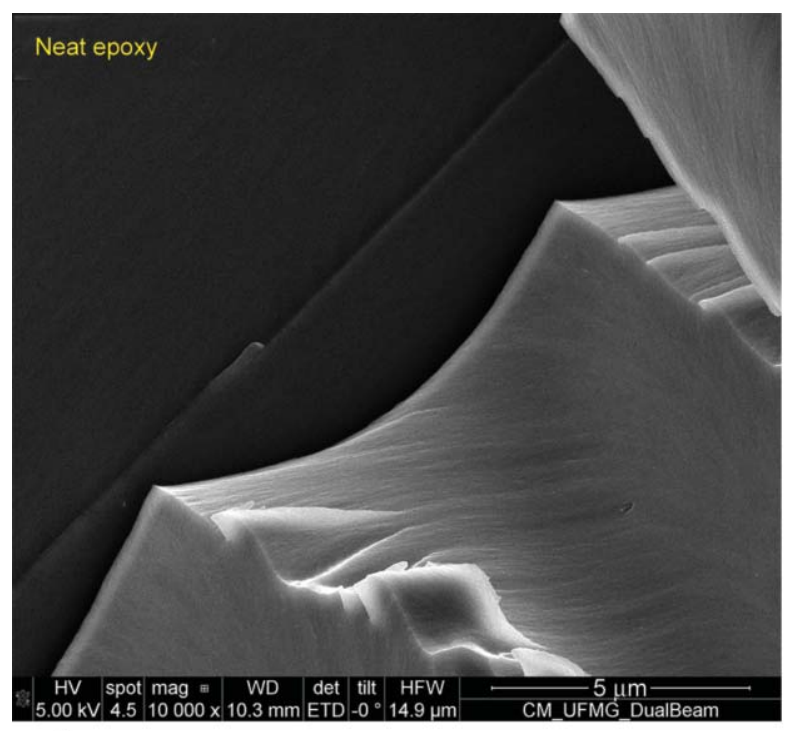

a)

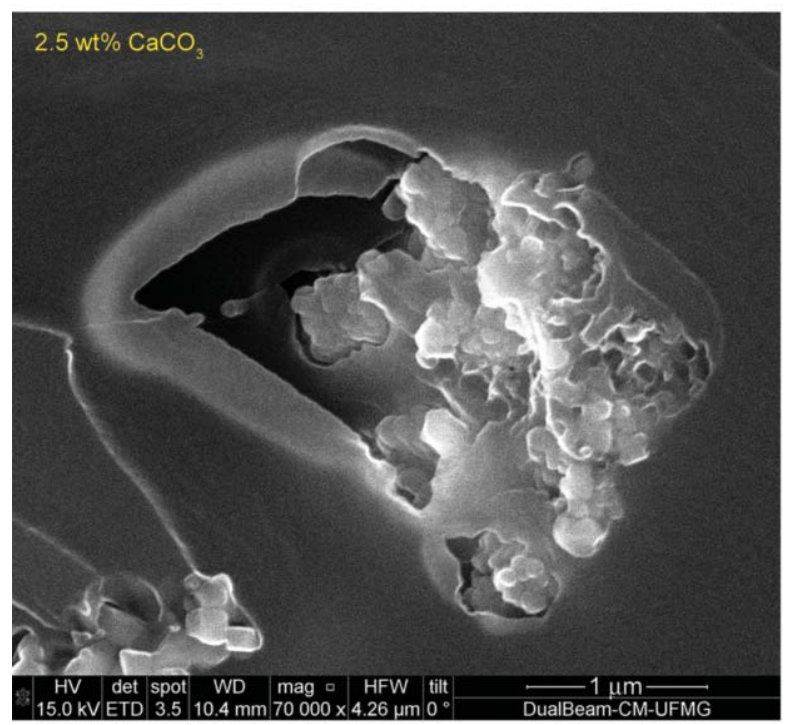

c)

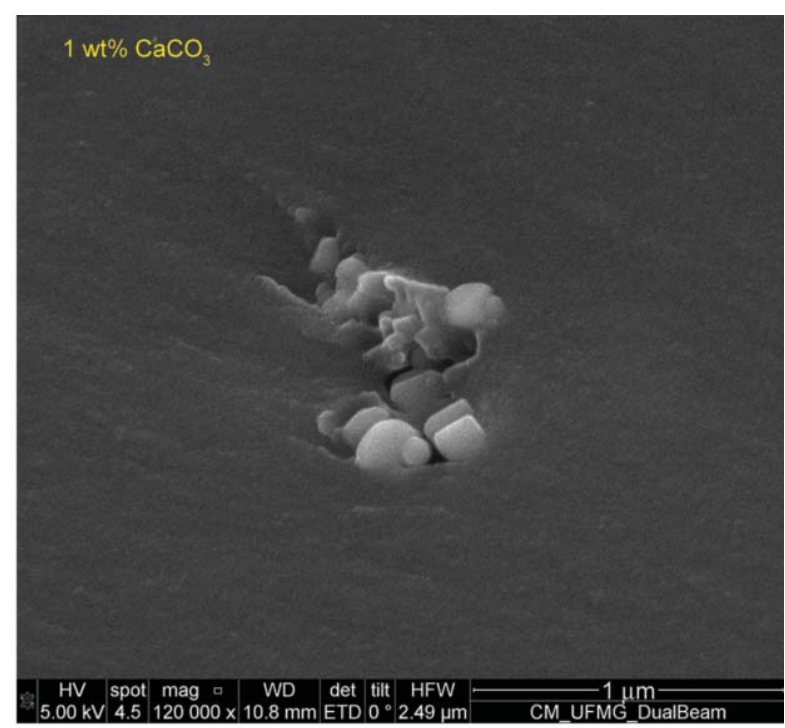

b)

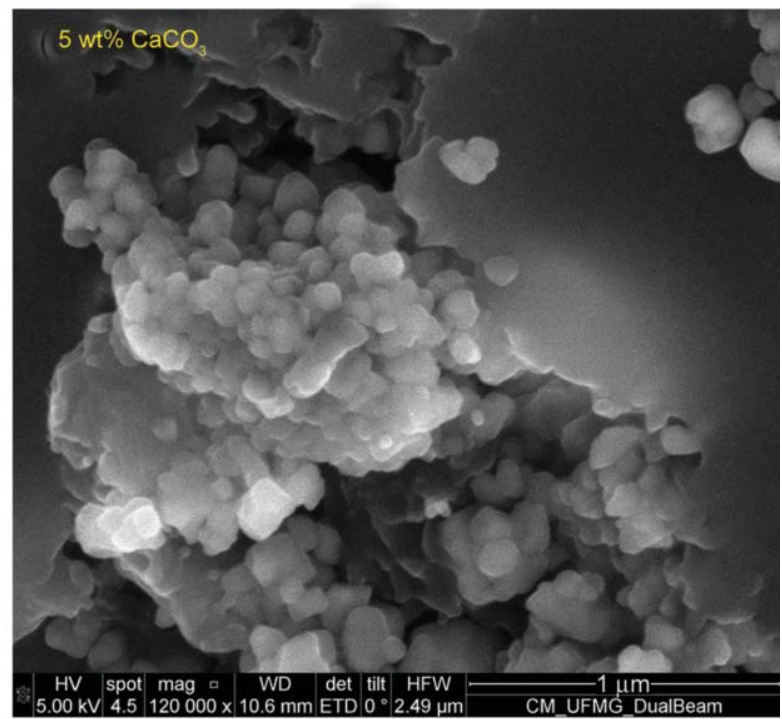

d)

Figure 6. SEM images at $1 \mu \mathrm{m}$ : (a) neat epoxy, (b) epoxy/1 wt $\% \mathrm{CaCO}_{3}$, (c) epoxy/2.5 wt $\% \mathrm{CaCO}_{3}$ and (d) epoxy/5 wt $\%$ $\mathrm{CaCO}_{3}$.

nanoparticles and micro-agglomerates can be observed. Therefore, the hierarchical structure of nano to micro-scale is characteristic of the composites prepared. Some defects were formed in the film of ultramicrotomed material due to the stiffness of the nanoparticles and the structures type channels are the carbon covered copper grid used as TEM substrate. Nanoindentation tests were performed to evaluate Young's modulus and hardness. Typical stress-strain curves for neat epoxy and composites are shown in Figure 8 . The average of numerical values of Young's modulus and hardness are presented in Figure 9 and Table 4 and have experimental uncertainty of $\pm 0.1 \mathrm{GPa}$ for modulus and $\pm 0.03 \mathrm{GPa}$ for hardness. All composites showed a significant increase in Young's modulus, higher than $32 \%$. Therefore, the
$\mathrm{CaCO}_{3}$ enhanced the stiffness of the composites as expected. Epoxy $/ 1 \mathrm{wt} \% \mathrm{CaCO}_{3}$ and epoxy $/ 2.5 \mathrm{wt} \%$ $\mathrm{CaCO}_{3}$ composites exhibited Young's modulus 45 and $59 \%$ greater, respectively, in comparison with the neat epoxy. These composites were also 31 and $38 \%$ harder, respectively. Epoxy $/ 5 \mathrm{wt} \% \mathrm{CaCO}_{3}$ composite did not show gains in hardness because of problems in the dispersion of nanoparticles.

Wettability refers to the study of how a liquid spreads when deposited on the surface of a substrate. There are two regimes of wettability: one in which the liquid spreads completely forming a film due to the high surface energy and another one in which the liquid droplet does not spread but forms a spherical layer on the surface of the substrate with an equilibrium contact angle, $\theta_{\mathrm{E}}$ [38]. The main factors that affect 


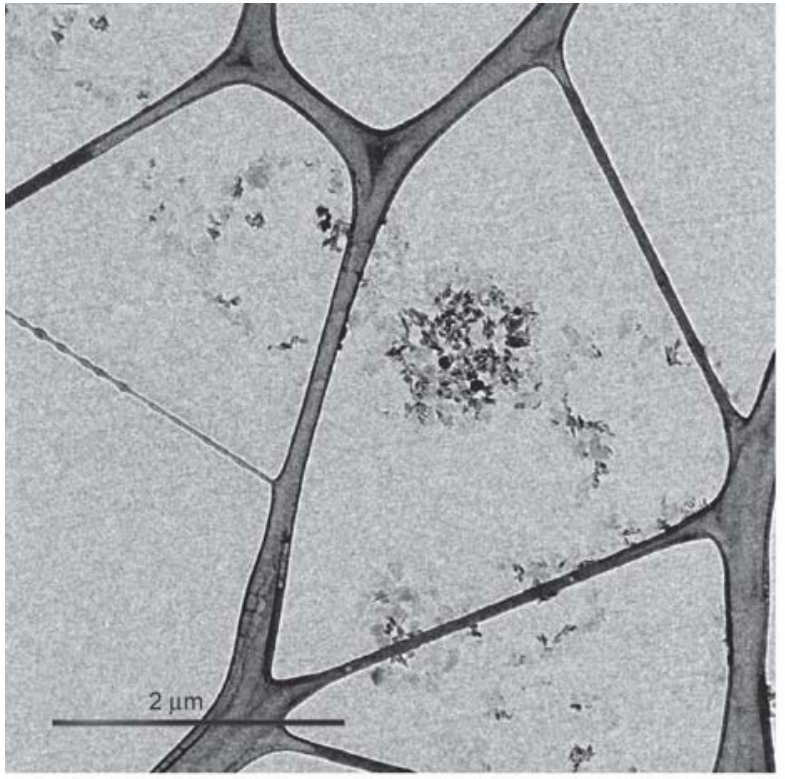

a)

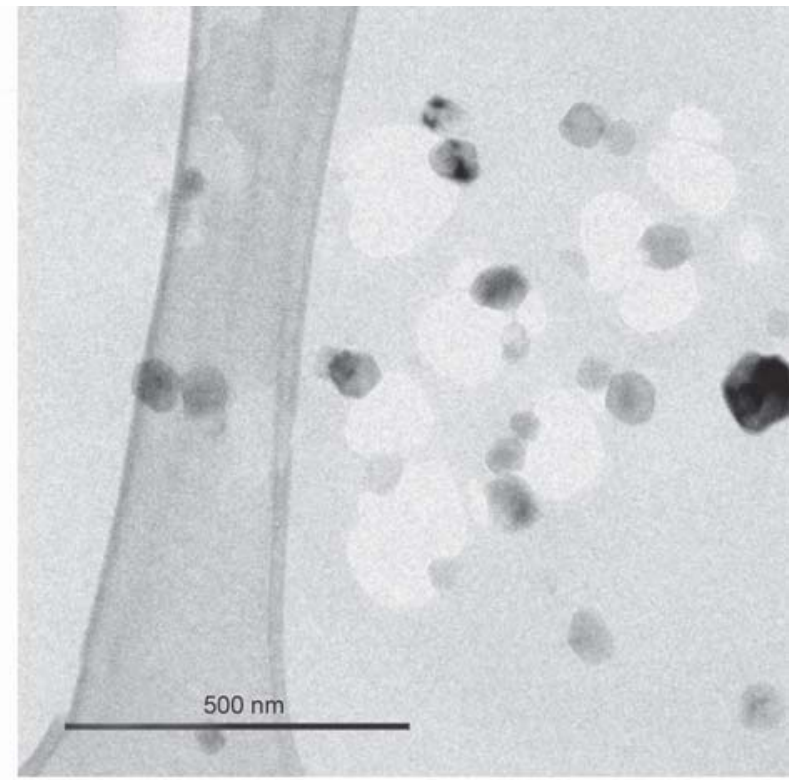

b)

Figure 7. TEM images of thin slices of epoxy $/ 2.5 \mathrm{wt} \%$ composite with scale bars: (a) $2 \mu \mathrm{m}$ and (b) $500 \mathrm{~nm}$.
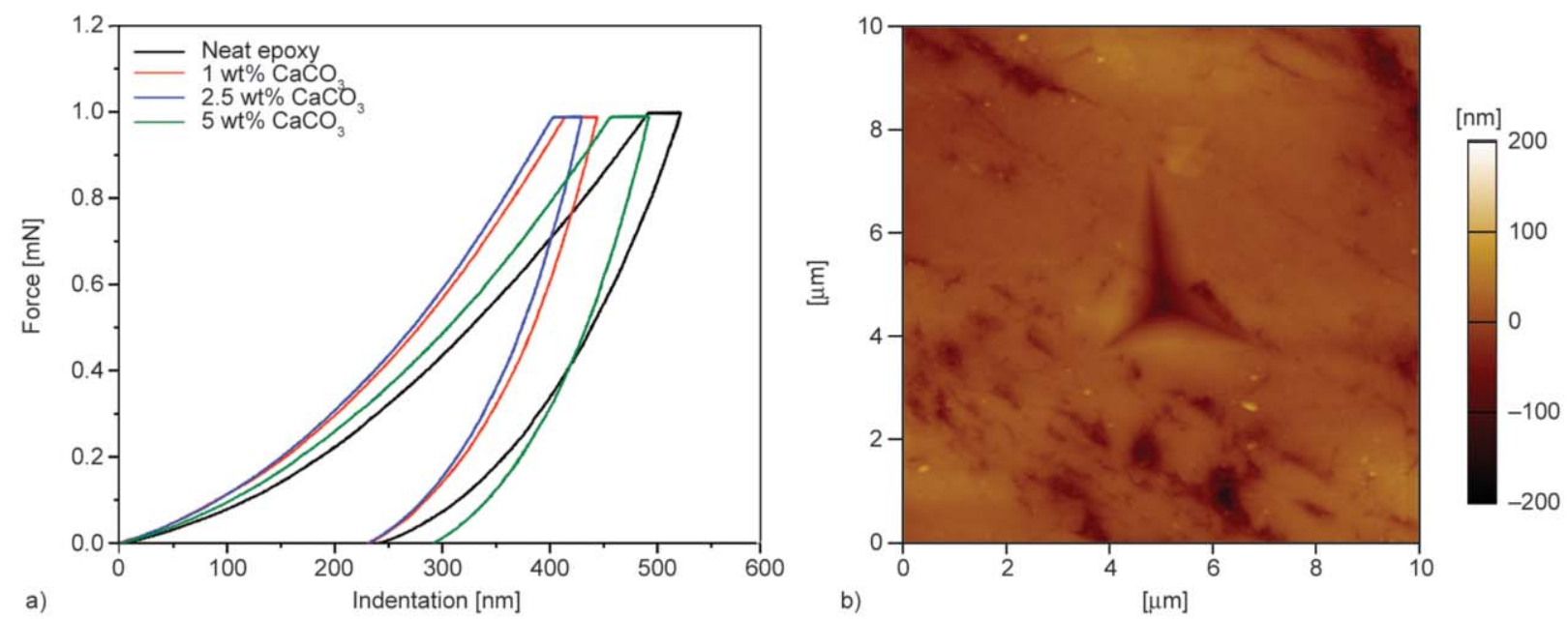

Figure 8. (a) Nanoindentation typical curves for neat epoxy and composites containing $1,2.5$ and $5 \mathrm{wt} \%$ of $\mathrm{CaCO}_{3}$ nanoparticles and (b) AFM image showing a mark of indentation.

the wettability of a chemically heterogeneous solid surface, as in the case of epoxy/nano $\mathrm{CaCO}_{3}$ composites, are surface energy and roughness $[39,40]$. Thus, when a droplet of water is deposited on a rough surface, for example, the appropriate combination of surface texture and surface energy may cause the liquid not to fully penetrate the surface texture, allowing the formation of air pockets under the droplet $[38,41]$. As a result, a composite interface between solid, liquid and air is set up.

The average results of the water contact angle (WCA) and the surface roughness (calculated statistically through the root mean square roughness, $R_{\mathrm{q}}$ ), determined by AFM, are presented in Figure $10 . \mathrm{CaCO}_{3}$ nanoparticles addition promoted an increase in WCA

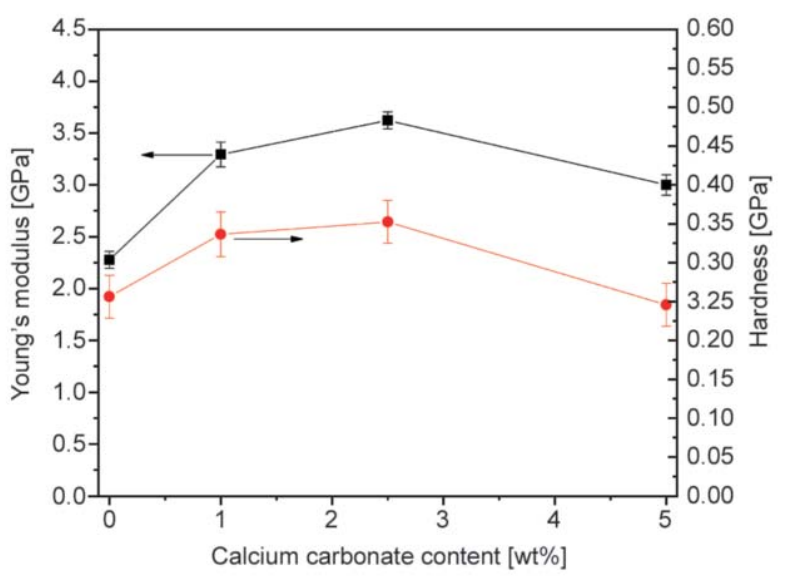

Figure 9. Young's modulus and hardness of neat epoxy and epoxy/nano $\mathrm{CaCO}_{3}$ composites. 
Table 4. Young's modulus and hardness of neat epoxy and epoxy/nano $\mathrm{CaCO}_{3}$ composites from Nanoindentation.

\begin{tabular}{|l|c|c|}
\hline \multicolumn{1}{|c|}{ Sample } & $\begin{array}{c}\text { Young's modulus } \\
\text { [GPa] }\end{array}$ & $\begin{array}{c}\text { Hardnesss } \\
\text { [GPa] }\end{array}$ \\
\hline Neat epoxy & $2.3 \pm 0.1$ & $0.26 \pm 0.03$ \\
\hline $1 \mathrm{wt} \% \mathrm{CaCO}_{3}$ & $3.3 \pm 0.1$ & $0.34 \pm 0.03$ \\
\hline $2.5 \mathrm{wt} \% \mathrm{CaCO}_{3}$ & $3.6 \pm 0.1$ & $0.35 \pm 0.03$ \\
\hline $5 \mathrm{wt} \% \mathrm{CaCO}_{3}$ & $3.0 \pm 0.1$ & $0.25 \pm 0.03$ \\
\hline
\end{tabular}

and composites roughness with respect to the neat epoxy. The AFM images with the line scans of the composites are shown in Figure 11 and illustrate their roughness profiles.

The exposure of the hierarchical micrometric structure of nanoparticles along with polymer chains enhanced surface roughness of the composites and contributed to the increase in WCA. Although the roughness seems to be the main factor leading to the decrease in wettability, there was a chemical effect that assisted the change in the surface energy, because the WCA continued increasing despite the roughness reduction of epoxy $/ 2.5 \mathrm{wt} \% \mathrm{CaCO}_{3}$ to epoxy $/ 5 \mathrm{wt} \% \mathrm{CaCO}_{3}$ composites.

The Cassie-Baxter equation (Equation (2)) was used to evaluate the relationship between the water contact angle (WCA) of a water droplet on the neat epoxy surface $(\theta)$ and that on a heterogeneous surface $\left(\theta_{\mathrm{r}}\right)$ composed of a solid and air established in the epoxy/ nano $\mathrm{CaCO}_{3}$ composites $[42,43]$ :

$\cos \theta_{\mathrm{r}}=f_{1} \cos \theta-f_{2}$

in which $f_{1}$ and $f_{2}$ are the fractions of the solid surface and air in contact with the liquid, respectively, and, $f_{1}+f_{2}=1$.

The WCA of neat epoxy, that has low surface energy, is $89^{\circ}$. Table 5 shows the calculations results and the increase in the fraction of the composite interface occupied by air with the increase of the WCA, suggesting that air is trapped between liquid and solid. Therefore, some $\mathrm{CaCO}_{3}$ nanoparticles aggregates are beneficial to the formation of the hydrophobic surface

Table 5. Water contact angles (WCAs), root mean square roughness $\left(R_{\mathrm{q}}\right)$ and solid surface and air fractions in contact with the liquid of the composites.

\begin{tabular}{|l|c|c|c|c|}
\hline \multicolumn{1}{|c|}{ Sample } & $\begin{array}{c}\text { WCA } \\
{\left[{ }^{\circ}\right]}\end{array}$ & $\begin{array}{c}\boldsymbol{R}_{\mathbf{q}} \\
{[\mathbf{n m}]}\end{array}$ & $\begin{array}{c}\text { Fraction of solid surface in contact } \\
\text { with the liquid }\left(\boldsymbol{f}_{\mathbf{1}}\right)\end{array}$ & $\begin{array}{c}\text { Fraction of air in contact with the } \\
\text { liquid }\left(\boldsymbol{f}_{\mathbf{2}}\right)\end{array}$ \\
\hline Neat epoxy & $89 \pm 5$ & $53 \pm 19$ & - & - \\
\hline $1 \mathrm{wt} \% \mathrm{CaCO}_{3}$ & $94 \pm 3$ & $101 \pm 11$ & 0.91 & 0.09 \\
\hline $2.5 \mathrm{wt} \% \mathrm{CaCO}_{3}$ & $97 \pm 4$ & $135 \pm 5$ & 0.86 & 0.14 \\
\hline $5 \mathrm{wt} \% \mathrm{CaCO}_{3}$ & $106 \pm 3$ & $114 \pm 37$ & 0.71 & 0.29 \\
\hline
\end{tabular}

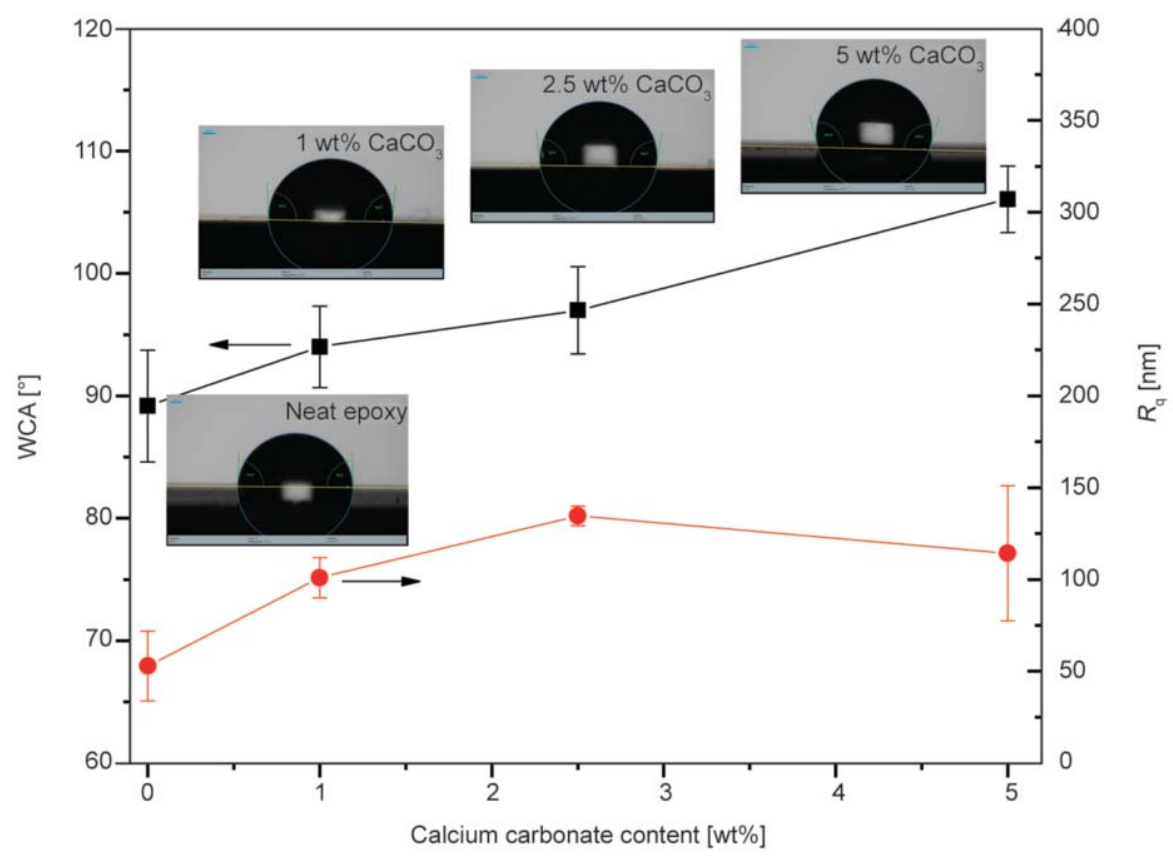

Figure 10. Water contact angles (WCAs) and root mean square roughness $\left(R_{\mathrm{q}}\right)$ of neat epoxy and epoxy/nano $\mathrm{CaCO} \mathrm{Com}_{3}$ posites. 

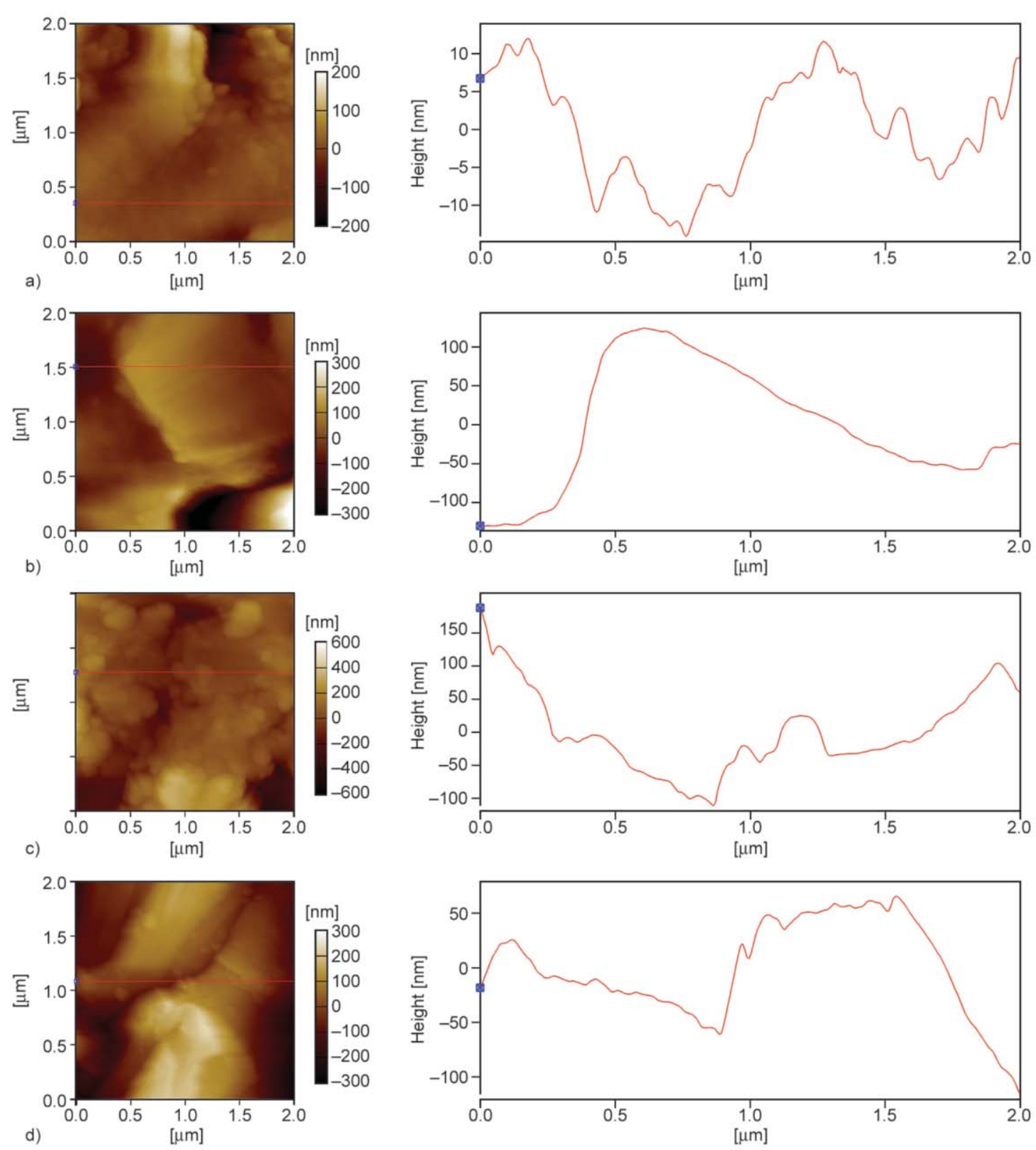

Figure 11. AFM images with the line scans of (a) neat epoxy, (b) epoxy $/ 1 \mathrm{wt} \% \mathrm{CaCO}_{3}$, (c) epoxy/2.5 wt $\% \mathrm{CaCO}_{3}$ and (d) epoxy $/ 5 \mathrm{wt} \% \mathrm{CaCO}_{3}$.

$[27,40,42]$. In addition, materials with more hydrophobic surfaces can improve their corrosion resistance and, as a result, have an increase in their working life.

\section{Conclusions}

A study of calcium carbonate nanoparticles synthesis, epoxy/nano $\mathrm{CaCO}_{3}$ composites production and assessment of resulting materials thermomechanical and surface properties were presented. The mechanochemical processing using a low energy mill $(100 \mathrm{rpm})$ proved to be capable of synthesizing calcium carbonate nanoparticles with calcite structure, cubic morphology, and low polydispersity. Since the reaction kinetics depends on the energy transferred from collisions, the low energy mill demands more time than high energy mills to achieve the same nanoscale structure of the final product. The mechanochemical processing employed, however, appears to be a successful method of nanoparticle synthesis on account of the homogeneous phase and morphology, nanometric particle size and few process parameters to control.

The incorporation of $\mathrm{CaCO}_{3}$ nanoparticles in the epoxy resin resulted in a hierarchical structure of micrometric sized extended aggregates of nanometric particles in the epoxy matrix. However, excessive or more aggressive dispersion processing, using solvents, for instance, could result in the thermal or 
structural commitment of the polymer network. Therefore, the hierarchical microstructure of nanoparticles was considered a good compromise to minimize tradeoffs among properties pursued in this work. Thermally stable composites with enhanced thermomechanical and surface properties were obtained and the results were consistent in indicating that the maximum of $2.5 \mathrm{wt} \%$ of nano $\mathrm{CaCO}_{3}$ was the optimum content to enhance properties. Some of the best results are more than $59 \%$ increase in stiffness by Nanoindentation and $12^{\circ} \mathrm{C}$ of glass transition enhancement. Moreover, an increase of hydrophobicity was characterized by the $\mathrm{CaCO}_{3}$ addition, which is important to the design of applications of the epoxy composites.

\section{Acknowledgements}

This work was supported by CAPES, CNPq, FAPEMIG and Centro de Tecnologia em Nanomateriais e Grafeno (CTNano/UFMG). The authors thank the images provided by Centro de Microscopia/UFMG.

\section{References}

[1] Petrie E. M.: Epoxy adhesive formulations. McGrawHill, New York (2006).

[2] Bikiaris D.: Can nanoparticles really enhance thermal stability of polymers? Part II: An overview on thermal decomposition of polycondensation polymers. Thermochimica Acta, 523 25-45 (2011). https://doi.org/10.1016/j.tca.2011.06.012

[3] Pascault J. P., Williams R. J. J.: Epoxy polymers: New materials and innovations. Wiley, Weinheim (2010).

[4] He H., Zhang Z., Wang J., Li K.: Compressive properties of nano-calcium carbonate/epoxy and its fibre composites. Composites Part B: Engineering, 45, 919-924 (2013).

https://doi.org/10.1016/j.compositesb.2012.09.050

[5] Tsuzuki T., Pethick K., McCormick P. G.: Synthesis of $\mathrm{CaCO}_{3}$ nanoparticles by mechanochemical processing. Journal of Nanoparticle Research, 2, 375-380 (2000). https://doi.org/10.1023/A:1010051506232

[6] Sargheini J., Ataie A., Salili S. M., Hoseinion A. A.: One-step facile synthesis of $\mathrm{CaCO}_{3}$ nanoparticles via mechano-chemical route. Powder Technology, 219, 7277 (2011).

https://doi.org/10.1016/j.powtec.2011.12.011

[7] Chan C-M., Wu J., Li J-X., Cheung Y-K.: Polypropylene/calcium carbonate nanocomposites. Polymer, 43, 2981-2992 (2002).

https://doi.org/10.1016/S0032-3861(02)00120-9

[8] McCormick P. G.: Application of mechanical alloying to chemical refining (overview). Materials Transactions, JIM, 36, 161-169 (1995).

https://doi.org/10.2320/matertrans1989.36.161
[9] Koch C. C., Whittenberger J. D.: Mechanical milling/ alloying of intermetallics. Intermetallics, 4, 339-355 (1996). https://doi.org/10.1016/0966-9795(96)00001-5

[10] Koch C. C.: Top-down synthesis of nanostructured materials: Mechanical and thermal processing methods. Reviews on Advanced Materials Science, 5, 91-99 (2003).

[11] McCormick P. G., Tsuzuki T., Robinson J. S., Ding J.: Nanopowders synthesized by mechanochemical processing. Advanced Materials, 13, 1008-1010 (2001). https://doi.org/10.1002/1521-4095(200107)13:12/13<1008:: AID-ADMA1008>3.0.CO;2-Q

[12] Tsuzuki T., McCormick P. G.: Mechanochemical synthesis of nanoparticles. Journal of Materials Science, 39, 5143-5146 (2004). https://doi.org/10.1023/B:JMSC.0000039199.56155.f9

[13] Pei L., Tsuzuki T., Dodd A., Saunders M.: Synthesis of calcium chlorapatite nanoparticles and nanorods via a mechanically-induced solid-state displacement reaction and subsequent heat treatment. Ceramics International, 43, 11410-11414 (2017).

https://doi.org/10.1016/j.ceramint.2017.05.350

[14] Achimovičová M., Godočíková E., Baláž P., Kováč J., Šatka A.: Influence of soluble salt matrix on mechanochemical preparation of $\mathrm{PbS}$ nanoparticles. Reviews on Advanced Materials Science, 18, 216-220 (2008).

[15] Jain R., Narula A. K., Choudhary V.: Studies on epoxy/ calcium carbonate nanocomposites. Journal of Applied Polymer Science, 114, 2161-2168 (2009). https://doi.org/10.1002/app.30292

[16] Li L., Zou H., Shao L., Wang G., Chen J.: Study on mechanical property of epoxy composite filled with nanosized calcium carbonate particles. Journal of Materials Science, 40, 1297-1299 (2005).

https://doi.org/10.1007/s10853-005-6956-7

[17] Shimpi N. G., Mishra S.: Sonochemical synthesis of mineral nanoparticles and its applications in epoxy nanocomposites. Polymer-Plastics Technology and Engineering, 51, 111-115 (2012).

https://doi.org/10.1080/03602559.2011.617407

[18] Ghosh G.: Dispersion-equation coefficients for the refractive index and birefringence of calcite and quartz crystals. Optics Communications, 163, 95-102 (1999). https://doi.org/10.1016/S0030-4018(99)00091-7

[19] Ghadam A. G. J., Idrees M.: Characterization of $\mathrm{CaCO}_{3}$ nanoparticles synthesized by reverse microemulsion technique in different concentrations of surfactants. Iranian Journal of Chemistry and Chemical Engineering, 32, 27-35 (2013).

[20] Tao H., He Y., Zhao X.: Preparation and characterization of calcium carbonate-titanium dioxide core-shell $\left(\mathrm{CaCO}_{3} @ \mathrm{TiO}_{2}\right)$ nanoparticles and application in the papermaking industry. Powder Technology, 283, 308-314 (2015).

https://doi.org/10.1016/j.powtec.2015.05.039 
[21] da Silva W. M., Ribeiro H., Neves J. C., Calado H. D. R., Garcia F. G., Silva G. G.: Multi-walled carbon nanotubes functionalized with triethylenetetramine as fillers to enhance epoxy dimensional thermal stability. Journal of Thermal Analysis and Calorimetry, 115, 1021-1027 (2014).

https://doi.org/10.1007/s10973-013-3519-Z

[22] Ribeiro H., Trigueiro J. P. C., Owuor P. S., Machado L. D., Woellner C. F., Pedrotti J. J., Jaques Y. M., Kosolwattana S., Chipara A., Silva W. M., Silva C. J. R., Galvão D. S., Chopra N., Odeh I. N., Tiwary C. S., Silva G. G., Ajayan P. M.: Hybrid 2D nanostructures for mechanical reinforcement and thermal conductivity enhancement in polymer composites. Composites Science and Technology, 159, 103-110 (2018).

https://doi.org/10.1016/j.compscitech.2018.01.032

[23] Oliver W. C., Pharr G. M.: An improved technique for determining hardness and elastic modulus using load and displacement sensing indentation experiments. Journal of Materials Research, 7, 1564-1583 (1992). https://doi.org/10.1557/JMR.1992.1564

[24] Wu G., Wang Y., Zhu S., Wang J.: Preparation of ultrafine calcium carbonate particles with micropore dispersion method. Powder Technology, 172, 82-88 (2007). https://doi.org/10.1016/j.powtec.2006.10.031

[25] Al-Hosney H. A., Grassian V. H.: Water, sulfur dioxide and nitric acid adsorption on calcium carbonate: A transmission and ATR-FTIR study. Physical Chemistry Chemical Physics, 7, 1266-1276 (2005). https://doi.org/10.1039/B417872F

[26] Andersen F. A., Brečević L.: Infrared spectra of amorphous and crystalline calcium carbonate. Acta Chemica Scandinavica, 45, 1018-1024 (1991). https://doi.org/10.3891/acta.chem.scand.45-1018

[27] Atta A. M., Al-Lohedan H. A., Ezzat A. O., Al-Hussain S. A.: Characterization of superhydrophobic epoxy coatings embedded by modified calcium carbonate nanoparticles. Progress in Organic Coatings, 101, 577-586 (2016).

https://doi.org/10.1016/j.porgcoat.2016.10.008

[28] Fuad M. Y. A., Hanim H., Zarina R., Mohd Ishak Z. A., Hassan A.: Polypropylene/calcium carbonate nanocomposites - Effects of processing techniques and maleated polypropylene compatibiliser. Express Polymer Letters, 4, 611-620 (2010).

https://doi.org/10.3144/expresspolymlett.2010.76

[29] Nanda K. K., Maisels A., Kruis F. E., Fissan H., Stappert S.: Higher surface energy of free nanoparticles. Physical Review Letters, 91, 106102/1-106102/4 (2003). https://doi.org/10.1103/PhysRevLett.91.106102

[30] Zare Y.: Study of nanoparticles aggregation/agglomeration in polymer particulate nanocomposites by mechanical properties. Composites Part A: Applied Science and Manufacturing, 84, 158-164 (2016). https://doi.org/10.1016/j.compositesa.2016.01.020

[31] He H., Li K., Wang J., Sun G., Li Y., Wang J.: Study on thermal and mechanical properties of nano-calcium carbonate/epoxy composites. Materials and Design, 32, 4521-4527 (2011).

https://doi.org/10.1016/j.matdes.2011.03.026
[32] Jin F-L., Park S-J.: Thermal stability of trifunctional epoxy resins modified with nanosized calcium carbonate. Bulletin of the Korean Chemical Society, 30, 334338 (2009).

https://doi.org/10.5012/bkcs.2009.30.2.334

[33] Camino G., Tartaglione G., Frache A., Manferti C., Costa G.: Thermal and combustion behaviour of layered silicate-epoxy nanocomposites. Polymer Degradation and Stability, 90, 354-362 (2005).

https://doi.org/10.1016/j.polymdegradstab.2005.02.022

[34] Shi Q., Wang L., Yu H., Jiang S., Zhao Z., Dong X.: A novel epoxy resin $/ \mathrm{CaCO}_{3}$ nanocomposite and its mechanism of toughness improvement. Macromolecular Materials and Engineering, 291, 53-58 (2006). https://doi.org/10.1002/mame.200500223

[35] Putz K. W., Palmeri M. J., Cohn F. B., Andrews R., Brinson L. C.: Effect of cross-link density on interphase creation in polymer nanocomposites. Macromolecules, 41, 6752-6756 (2008). https://doi.org/10.1021/ma800830p

[36] Hong S-G., Wu C-S.: DSC and FTIR analyses of the curing behavior of epoxy/dicy/solvent systems on hermetic specimens. Journal of Thermal Analysis and Calorimetry, 59, 711-719 (2000). https://doi.org/10.1023/A:1010189301221

[37] Lau K-T., Lu M., Lam C-K., Cheung H-Y., Sheng F-L., Li H-L.: Thermal and mechanical properties of singlewalled carbon nanotube bundle-reinforced epoxy nanocomposites: The role of solvent for nanotube dispersion. Composites Science and Technology, 65, 719-725 (2005). https://doi.org/10.1016/j.compscitech.2004.10.005

[38] De Gennes P. G., Brochard-Wyart F., Quéré D.: Capillarity and wetting phenomena. Springer, New York (2004).

[39] Miwa M., Nakajima A., Fujishima A., Hashimoto K., Watanabe T.: Effects of the surface roughness on sliding angles of water droplets on superhydrophobic surfaces. Langmuir, 16, 5754-5760 (2000). https://doi.org/10.1021/la991660o

[40] Liu Y., Lin Z., Lin W., Moon K. S., Wong C. P.: Reversible superhydrophobic-superhydrophilic transition of $\mathrm{ZnO}$ nanorod/epoxy composite films. ACS Applied Materials and Interfaces, 4, 3959-3964 (2012). https://doi.org/10.1021/am300778d

[41] Choi W., Tuteja A., Mabry J. M., Cohen R. E., McKinley G. H.: A modified Cassie-Baxter relationship to explain contact angle hysteresis and anisotropy on non-wetting textured surfaces. Journal of Colloid and Interface Science, 339, 208-216 (2009).

https://doi.org/10.1016/j.jcis.2009.07.027

[42] Zhang H., Zeng X., Gao Y., Shi F., Zhang P., Chen J-F.: A facile method to prepare superhydrophobic coatings by calcium carbonate. Industrial and Engineering Chemistry Research, 50, 3089-3094 (2011). https://doi.org/10.1021/ie102149y

[43] Hu Z., Deng Y.: Superhydrophobic surface fabricated from fatty acid-modified precipitated calcium carbonate. Industrial and Engineering Chemistry Research, 49, 5625-5630 (2010). https://doi.org/10.1021/ie901944n 